\title{
Research on the Application of Econometric Model Parameters in Measuring the Internalization Degree of Industrial Positive Externalities
}

\author{
Huilu Yu*\#, Suocheng Dong'**, Hongping Fei ${ }^{3}$, Fei $\mathbf{L i}^{2 \#}$, \\ Xiaorong Guan ${ }^{1}$, Shuguang Jiang ${ }^{1}$ \\ ${ }^{1}$ School of Resources and Environmental Engineering, Ludong University, Yantai 264025, China \\ ${ }^{2}$ Institute of Geographic Sciences and Natural Resources Research, Chinese Academy of Sciences, \\ 11A Datun Road, Anwai, Chaoyang District, Beijing 100101, China \\ ${ }^{3}$ Research Institute of Industrial and Technological Economy, Macroeconomic Research Institute of China, \\ Beijing 100038, China
}

Received: 10 June 2021

Accepted: 12 June 2021

\begin{abstract}
The use of the internalization degree of positive externalities has been proposed as an evaluation standard of the performance of government fiscal expenditure for energy conservation and environmental protection. This paper takes the positive externality activity of the regional industry as a system, and employs econometric models based on panel data of prefecture-level cities in an assumed Province to analyze the effects of energy conservation and pollutant emission reduction caused by this governmental expenditure in the industry system. In the estimated econometric model that relevant data are all processed in logarithm, the meaning of the parameter before an explanatory variable is the elasticity of the explained variable to the change rate of the explanatory variable. That is, if we obtain the change rate of an explanatory variable, the change rate of explained variable caused by the explanatory variable's change can be obtained under the condition that other variables remain unchanged. In turn, the relationship between explained variable and explanatory variables is still true within the observation period. On the basis of knowing the change rate of the explained variable, the share of change caused by a certain explanatory variable can be calculated. According to this logic, the share caused by government fiscal expenditure can be separated from the total industrial energy conservation and pollutant emission reduction, and this can be used as the basic data for the performance evaluation of fiscal expenditure for energy conservation and environmental protection. We establish a set of methods to calculate
\end{abstract}

\footnotetext{
\# The authors contributed equally to this study.

*e-mail: yuhuilu73@163.com

**e-mail: dongsc3@163.com
} 
the positive externalities of industry activity and assess its internalization degree fulfilled by governmental fiscal expenditure for resource conservation and environmental protection.

Keywords: positive externality, fiscal expenditure for energy conservation and environmental protection, environmental value, performance evaluation

\section{Introduction}

At present, public goods theory and externality theory are generally regarded as the basic theoretical support of related research in academic circles. The theory of public goods can explain the rationality and necessity of this fiscal expenditure. The theory of externality can provide a basis for judging the reasonable degree of fiscal expenditure. After all, improving environmental quality requires government intervention in the production or consumption behavior of economic activity subject. However, there are limits to this government intervention. According to the externality theory of environmental economics, the internalization of externality is the basic way to optimize resource allocation. The government can internalize the negative externalities of enterprise production by levying pollution fees and other means, or guide enterprises to increase investment in economic fields with positive externalities such as energy conservation and pollutant emission reduction by means of preferential policies and financial subsidies, so as to achieve the goal of improving environmental quality. Once the governmental intervention in economic activities exceeds the scope of internalization of externalities, the governmental intervention will reduce the efficiency of market's resource allocation $[1,2]$.

However, with internalization of externality as the prerequisite basis for judging the performance of fiscal environmental expenditure, we must first estimate the externality scale generated by the relevant economic activities. Now, many scholars in the field of environmental management have begun to study the issue of industry policy's rationality and optimization from the perspective of monetization evaluating externality. Ding et al. (2014) constructed a measurement model of internalization of externalities based on methods of Life Cycle Assessment (LCA) and net present value (NPV) analysis to explore the reasonable subsidy space for promoting the development of new energy vehicles [3]. Eidelwein et al. (2018) proposed a method for internalizing the enterprise's externality by using the income statement. The research result shows that the cost of environmental externality is equivalent to $12.5 \%$ of the enterprise's net income during the evaluation period [4]. Comparatively speaking, there are few research results on the internalization of external costs from the perspective of green products or enterprises, which is still in its infancy stage [5-7].
Quoting environmental cost parameters from other research results, Štreimikiene (2017) studies the issues of environmental externalities and their internalization in the energy sector of the Baltic States, and revealed the complex relationship between the internalization effects of externalities generated by subsidy policies, environmental taxes and various contextual conditions such as the natural environment, society, economy, and politics [8]. Taking the supply chain as study object, Ding et al. (2016) explored the issue of government policies' optimization on promoting enterprises' environmental investments by introducing multiple constraints in the model (i.e. Environmental Externalities and Stakeholders' Environmental Interests). From the perspective of the supply chain, this paper discusses the impact of multiple constraints on the economic feasibility of environmental investment and the potential to reduce externalities [9]. Wang et al. (2017) established a model of internalization of logistics' negative external cost, and quantitatively analyzed the relationship between freight rates, freight volume, and the investments of enterprises in implementing green logistics. On the basis of comparing the two modes of "enterprise operation first" and "government subsidy first", this paper analyzes the effect of government subsidies. The results show that the introduction of "government subsidy first" incentives and higher freight rates have contributed to the greening progress of logistics markets [10]. The above research basically explore a quantitative method of internalization of externalities from the perspective of industry and industrial chain. The trend of such research is growing [11-13].

Some studies of energy models at global and regional scales, such as those by Klaassen and Riahi (2007) [14], Holmgren and Amiri (2007) [15], and Nguyen (2008) [16], have attempted to internalize external costs, involving both global warming and other environmental issues. These studies use the results of the European Commission's ExternE project (Friedrich and Bickel, 2001) [17] based on the results of life cycle impact assessments (LCAs) for environmental externality estimation, but the environmental externalities covered in the model are limited to the impact of sulfur oxides, nitrogen oxides, and particulate matter from energy supply systems. The analytical framework and the evaluation model proposed by the above-mentioned studies provide a useful reference for the study of global or regional externality internalization from the macro level. However, the research results at the macro level lag far behind those at the micro-enterprise level 
Table 1. Abbreviations of professional terms.

\begin{tabular}{|c|c|}
\hline Professional terms & Abbreviation \\
\hline Fiscal expenditure for energy conservation and environmental protection & FEECEP \\
\hline Resource saving and pollutant emission reduction & RSPER \\
\hline Chemical oxygen demand & NO $_{x}$ \\
\hline Nitrogen oxide & R\&D \\
\hline Research and development & SO $_{2}$ \\
\hline Sulfur dioxide & LCA \\
\hline Life Cycle Assessment & NPV \\
\hline Net present value & GDP \\
\hline Gross Domestic Product & \\
\hline
\end{tabular}

and the meso-industrial level, which is related to the characteristics of positive externalities. Taking circular economy as an example, the circular economy system at the enterprise level and supply chain level has the characteristics of clear boundaries and relatively complete input-output data, so it is feasible to conduct study of "internalization of positive externalities". However, the boundary of the circular economy system at the macro level is relatively blurred [18], and it is very difficult to clarify the input-output relationship of the system, which is an important reason for the slow progress of the study of "internalization of positive externalities" of the circular economy at the macro level.

This study employs econometric methods to overcome the problem that the system boundary of economic activity with positive externalities is blurred at the macro level. Taking the impact of government fiscal expenditure for energy conservation and environmental protection (FEECEP) (Table 1) on the effect of resource saving and pollutant emission reduction (RSPER) in the industrial field as the research object, we explore a set of methods which can calculate the scale of positive externality measured in currency caused by enterprises' activity based on econometric models, and judge to what extent the positive externality has been internalized by government fiscal expenditure for energy conservation and environmental protection.

\section{Methodology}

Taking the Degree of Positive Externality Internalization as the Theoretical Basis of Efficiency Evaluation Criteria

Without considering the social benefits of increasing employment (the social realization of full employment), the positive externalities of enterprise activity, such as the development of a circular economy, are mainly expressed through two channels: resource saving and pollutant emission reduction. Resource saving is mainly reflected in two aspects: water saving and energy saving. Its economic benefits (water saving $\times$ water price + energy saving $\times$ energy price) are obtained by enterprises as a cost saved and do not belong to the category of positive externality, but the environmental value generated by resource saving should be counted as a part of positive externality. The environmental value of energy saving is manifested in the reduction of pollutant emissions, the amount of which is equal to the pollutants emitted by the same amount of energy consumption. The environmental value of water saving can be regarded as reducing the discharge of water pollutants, and the amount is equal to the content of pollutants in the same amount of industrial wastewater that meets national standards. As the pollutant emission reduction effect of the main pollutants emissions caused by energy saving has been embodied in the decline of pollutant emission intensity per unit of industrial value-added per year, when calculating the positive externalities of this kind of enterprise activity, instead of repeatedly calculating the pollutant emission reduction effect, the greenhouse gas emission reduction should be calculated.

According to the theory of externality, the private benefits of economic activity with positive externalities are less than the social benefits, and enterprises are short of motion to implement this kind of activity. In order to promote the sustainable and healthy development of this kind of activity, the government must give enterprises some preferential policies or subsidies to make up for their loss of benefits, so that the social benefits of this kind of enterprise activity are equal to their private benefits. From the perspective of the market economy, if the effects of enterprise activity with positive externalities are defined in two aspects, i.e. RSPER, then a market will be formed in this field. The main commodity in this market is the effects of RSPER, whose price is the monetized measurement of this kind of positive externalities, i.e. the environmental value of resource saving and emission reduction of 
pollutants. In this market, the government is the only buyer, and the sellers are mainly enterprises. From the perspective of government macro-control, the driving force for the development of enterprises' activity with positive externalities is the regional government. In order to guide enterprises to participate in the capacity construction of energy conservation and environmental protection such as circular economy, which bears the characteristic of positive externalities, regional government provides enterprises preferential policies or fiscal subsidies to compensate them for their loss of benefits because of their economic activity with positive externalities. The governmental input is preferential policies or fiscal subsidies. The output is the effect of resource saving and pollutant emission reduction. In a sense, the enterprises' activity with positive externality can be regarded as the product of the regional government, the government input can be regarded as the cost, and the positive externality can be regarded as the benefit of the local government. With reference to the cost-benefit curve of enterprise production in economics, it is possible to draw a cost-benefit curve (governmental cost-benefit curve), which depicts governmental cost and benefit when it takes action to promote the development of enterprises' activity with positive externalities (Fig. 1). As this fiscal expenditure is the main source of funds to promote the development of enterprises' activity with positive externalities, the cost-benefit curve can provide research ideas and methods for a performance evaluation.

In the field of resource saving and pollutant emission reduction, the only buyer in the market is the local government. The traded goods in the market are positive externalities, which are the environmental value generated by resource saving and pollutant emission reduction. The supply scale of the positive externalities in the market depends on the price that the government is willing to offer, which in this case refers to the strength of incentives or fiscal subsidies. Compared with enterprise, the criterion of government decision-making is not the maximization of positive externality (benefit) but rationalization. According to the logical thinking of externality internalization, the standard of rationalization should be that the preferential policy or support provided by the government is equal to the monetized positive externality of enterprises' activity. In other words, the average cost invested by the government in the field of enterprises' activity with positive externality should be equal to the average income. Under the condition of the market economy, enterprises pursue profit maximization. Theoretically, the positive externality provided by enterprises will only be lower than or equal to the benefits brought by government financial subsidies or preferential policies. Therefore, one of the most important features of the governmental cost-benefit curve is that the average cost is always higher than the average benefit and the two curves have only one intersection point (i.e. the $\mathrm{G}$ point in Fig. 1). On the left side of $G$, such as $Q_{1}$, enterprises

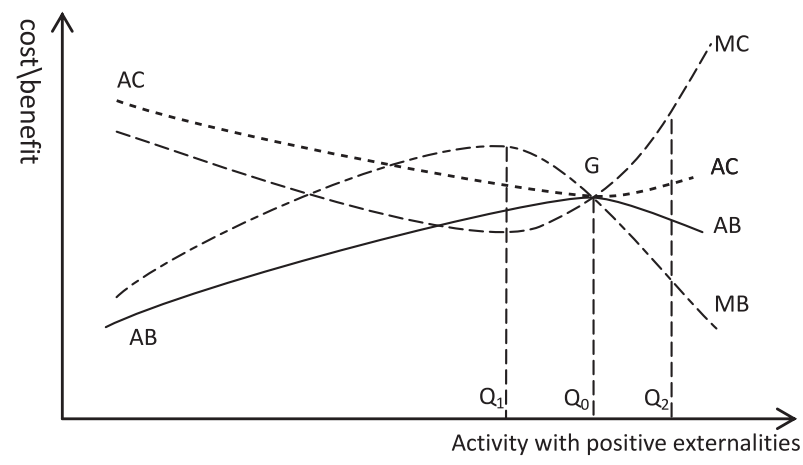

Fig. 1. The characteristics of the cost-benefit curve of positive externality activity.

lack the motivation to implement the activity of resource saving and pollutant emission reduction; on the right side of $G$, such as $Q_{2}$, the enterprise actively implements this kind of activity, but the government has the problem of inefficient fiscal expenditure in this field, which increases the fiscal burden and reduces the allocation efficiency of the resource market. Like the cost-benefit curve of ordinary industrial products, the marginal cost (MC) of regional enterprises' activity with positive externalities decreases and then increases, and intersects with the average cost (AC) curve at its lowest point. The marginal benefit curve (MB) shows a trend of rising at first and then decreasing, and intersects with the average benefit curve $(\mathrm{AB})$ at its highest point. In this way, four curves, i.e. $\mathrm{MC}, \mathrm{AC}, \mathrm{MB}, \mathrm{AB}$, have a common point of intersection, which is one of the most important characteristics of the governmental cost-benefit curve.

In particular, it should be noted that the $\mathrm{AB}$ starts to decline after reaching its maximum at point $\mathrm{G}$ (i.e. the point where $\mathrm{AC}$ is equal to $\mathrm{AB}$, which is also the point where positive externalities are fully internalized), which is viewed from the perspective of governmental incentives (fiscal subsidies and preferential policies). Once the incentives provided by regional government exceed the positive externalities that can be obtained, the governmental incentive would bring forth a negative effect, which is to reduce the efficiency of the allocation of resources in the market. From the perspective of enterprises, with the support of government preferential policies, it becomes profitable to carry out activity with positive externalities, and more resources will be invested in this field to make a profit. The average cost curve (AC) begins to rise after reaches its lowest point $G$, which is also viewed from the perspective of governmental behavior. After exceeding G, the government fiscal expenditure performance begins to decline. If the performance of FEECEP is evaluated by internalization degree of positive externalities, the closer the governmental input and output are to point $\mathrm{G}$, the higher the performance of expenditure, and the farther away from point $G$, the lower the performance of expenditure. 
Taking the internalization degree of positive externality as the performance evaluation standard of government FEECEP, we must first obtain the amount of resource saving and pollutant emission reduction caused by this expenditure. The analysis method of econometrics can provide method guidance for calculating the amount of resource conservation and emission reduction caused by this expenditure.

\section{The Economic Implication and Application of the Econometric Model}

The regression analysis of econometrics is a typical black-box approach in which the quantitative relationships between the main variables can be deduced simply by knowing the data on inputs and outputs of the system. There must be a solid theory as a support for the determination of the causal relationship between the explanatory variables and the explained variable in the regression model.

Taking the regional industrial economy as a system, the governmental investment in energy conservation and environmental protection can be taken as explanatory variables, and the pollutant emission intensity, energy consumption intensity, and water consumption intensity per unit of industrial value added can be taken as explained variables. The quantitative relationship between them is determined by the estimated econometric model, and according to the economic meaning of the regression coefficient, and the scale of resource saving and pollutant emission reduction caused by government investment in energy conservation and environmental protection is then calculated. Under the condition of market economy, this amount of resource saving and pollution reduction can be approximately regarded as the positive externality of enterprise-related economic activity. By obtaining the environmental value data produced by unit pollutant emission reduction and unit resource saving as well as the data of government FEECEP, we can calculate the internalization degree of positive externalities of enterprise-related economic activity. Furthermore, it can be used as a key indicator to evaluate the performance of this government expenditure in the industrial field.

If we obtain the data of government investment in an industrial sector with positive externalities, such as the amount of fiscal expenditure in the field of desulfurization, the amount of sulfur dioxide emission reduction caused by government input can be calculated by estimating the econometric model. Take the sulfur dioxide emission intensity ( $\mathrm{emso}_{\mathrm{t}}$ ) of unit industrial added value in t-period (year) as the explained variable, taking the logarithm of its value and expressing it with symbol LNemso. Take the government desulfurization fiscal expenditure (escot $t_{t}$ ) in t-period (year) as the core explanatory variable, taking the logarithm of its value and using the symbol $\mathrm{LNecso}_{\mathrm{t}}$ to represent its value. Suppose that, in addition to core explanatory variable $\mathrm{LNecso}_{t}$, three non-core explanatory variables are considered, and the data are also logarithmically processed, which are represented by symbols $\mathrm{LNx}_{\mathrm{t}}$, $\mathrm{LNx} 2_{t}$ and $\mathrm{LNx} 3_{t}$. The explanatory variables are used to do regression analysis on the explanatory variables, and the following model is obtained.

LNemso $_{t}=\beta_{1}+\beta_{2} L N e c s o_{t}+\beta_{3} L N x 1_{t}+\beta_{4} L N x 2_{t}+\beta_{5} L N x 3_{t}+u_{t}$

Because of the logarithmic processing of the data, the parameter $\beta_{2}$ bears the meaning of the elasticity of sulfur dioxide emission intensity $\left(\mathrm{emso}_{\mathrm{t}}\right.$ ) per unit of industrial added value to the change rate of government fiscal desulfurization expenditure (escot $t$ ) under the premise that other conditions remain unchanged [19]. This effect of the change of explanatory variables is a partial effect, which has strong constraints; that is, it is necessary to ensure that other conditions remain unchanged, which greatly limits the application value of the parameters. On the basis of the relative clarity of the mechanism of pollutant emission reduction, we can construct a set of methods to overcome the inherent limitations of the partial effect of the econometric model parameters. Relying on the model parameters' meaning of elasticity, the amounts of resource saving and pollutant emission reduction caused by government expenditure for energy conservation and environmental protection can then be calculated.

\section{Variable Selection and Model Assumption}

\section{Variable Selection and Data Description}

This study takes the FEECEP of $n$ prefecturelevel cities in an assumed Province of some country in the world from $T_{1}$ to $T_{2}$ as the research object. We assume that it is impossible to judge how much fiscal resources have been invested respectively in every fields of industrial pollutant emission reduction because that the current FEECEP in these prefecture-level cities does not have detailed sub-sector data. The emission reduction effect on various industrial pollutants can only be estimated according to the overall data of this expenditure.

Assuming that government FEECEP was allocated into $m$ kinds of industrial pollutant emission reduction, and the structure of government expenditure in this field is relatively stable during the study period, the quantitative relationship between pollutant emission intensity per unit of industrial value added or resource consumption intensity and government FEECEP can be estimated (i.e. the elasticity of the former with respect to the latter's inter-annual variability), which plays a decisive role in estimating the amounts of resource saving and pollutant emission reduction caused by this expenditure. By obtaining the data of running cost of pollution treatment facilities and amount of pollutant removal, the average processing cost of every pollutants can be obtained, which can be approximately regarded 
as the environmental value of emission reduction per unit of pollutants. With the above data, we can monetize the environmental value of resource saving and pollutant emission reduction caused by this expenditure, which is equivalent to the positive externality of the relevant economic activities of industrial enterprises, as shown in Formula (1).

$$
Q_{i, t}=\sum_{j=1}^{m}\left(e x_{i, j, t} \times p_{i, j}\right)
$$

$Q_{i, t}$ is the environmental value of resource saving and emission reduction caused by government FEECEP in the $t$-period of city $i, e x_{i, j, t}$ is the amount of the $j$ kind of pollutant emission reduction or resource saving caused by government FEECEP in the $t$-period of city $i$, and $p_{i, j}$ is the unit environmental value produced by $j$ kind of pollutant or resource when its emission was reduced or its consumption was saved in city $i$.

Taking into account the availability of data and the governmental emphasis on different types of industrial pollutants, this study selects the consumption amounts of energy and water, the emission amounts of sulfur dioxide, nitrogen oxides, smoke and dust, chemical oxygen demand, and ammonia nitrogen as the objects of analysis. The market value of greenhouse gas (carbon dioxide) emission reduction caused by energy conservation is also taken into account when calculating the scale of positive externalities.

Generally speaking, because different industries have different resource consumption intensity (resources consumed per unit output) and pollutant emission intensity (pollutant emissions per unit output), energy saving and pollutant emission reduction can also be achieved through industrial structure adjustment, reducing industries with high consumption and high pollution and increasing the proportion of green and low-carbon industries. However, in the short term, such as taking the year as the investigation cycle, the range of regional industrial structure changes is very limited. Some research results show that the effect of industrial

Table 2. Explanatory variables and explained variables.

\begin{tabular}{|c|c|c|c|}
\hline Category & Variable & Symbol & Description \\
\hline \multirow{7}{*}{$\begin{array}{l}\text { Explained } \\
\text { variable }\end{array}$} & $\begin{array}{c}\text { Energy consumption intensity / tce / } \\
\text { thousand US\$ }\end{array}$ & LNenergy $_{t}$ & $\begin{array}{l}\text { Industrial energy consumption amount/ values added of indus- } \\
\text { trial enterprises above designated size (take the logarithm) }\end{array}$ \\
\hline & $\begin{array}{l}\text { Water consumption intensity / ton / } \\
\text { thousand US\$ }\end{array}$ & $\mathrm{LNh}_{2} \mathrm{o}_{\mathrm{t}}$ & $\begin{array}{l}\text { Industrial water consumption amount / values added of indus- } \\
\text { trial enterprises above designated size (take the logarithm) }\end{array}$ \\
\hline & $\begin{array}{l}\text { Sulfur dioxide emission intensity / ton } \\
\text { / million US\$ }\end{array}$ & LNemso $_{\mathrm{t}}$ & $\begin{array}{l}\text { Industrial sulfur dioxide emission amount / values added of } \\
\text { industrial enterprises above designated size (take the logarithm) }\end{array}$ \\
\hline & $\begin{array}{l}\text { Nitrogen oxide emission intensity / } \\
\text { ton / million US\$ }\end{array}$ & LNemnox $_{t}$ & $\begin{array}{l}\text { Industrial nitrogen oxide emission amount / values added of } \\
\text { industrial enterprises above designated size (take the logarithm) }\end{array}$ \\
\hline & $\begin{array}{l}\text { Ammonia nitrogen emission ef- } \\
\text { ficiency / thousand US\$ / ton }\end{array}$ & LNemand $_{t}$ & $\begin{array}{l}\text { values added of industrial enterprises above designated size / in- } \\
\text { dustrial ammonia nitrogen emission amount (take the logarithm) }\end{array}$ \\
\hline & $\begin{array}{l}\text { Smoke and dust emission intensity / } \\
\text { ton / million US\$ }\end{array}$ & LNemyan $_{t}$ & $\begin{array}{l}\text { Smoke and dust emission amount / values added of industrial } \\
\text { enterprises above designated size (take the logarithm) }\end{array}$ \\
\hline & $\begin{array}{c}\text { COD emission intensity / ton / million } \\
\text { US\$ }\end{array}$ & LNemcod $_{t}$ & $\begin{array}{l}\text { COD emission amount / values added of industrial enterprises } \\
\text { above designated size (take the logarithm) }\end{array}$ \\
\hline \multirow{6}{*}{$\begin{array}{l}\text { Explanatory } \\
\text { variable }\end{array}$} & $\begin{array}{l}\text { Fiscal expenditure on energy } \\
\text { conservation and environmental } \\
\text { protection/ thousand US\$ }\end{array}$ & $\mathrm{LNec}_{\mathrm{t}}$ & $\begin{array}{l}\text { Local government budgetary expenditure on energy conserva- } \\
\text { tion and environmental protection (take the logarithm) }\end{array}$ \\
\hline & $\mathrm{R} \& \mathrm{D} /$ thousand US\$ & $\mathrm{LNrd}_{t}$ & $\begin{array}{l}\text { Expenditures of Industrial Enterprises above Designated Size on } \\
\qquad R \& D \text { (take the logarithm) }\end{array}$ \\
\hline & Fiscal decentralization $/ \%$ & $\mathrm{LNcf}_{\mathrm{t}}$ & $\begin{array}{c}\text { Local government budgetary expenditure / local government } \\
\text { budgetary revenue (take the logarithm) }\end{array}$ \\
\hline & $\begin{array}{l}\text { Proportion of state-owned enterprises } \\
\text { in industrial enterprises } / \%\end{array}$ & LNgp $_{t}$ & $\begin{array}{l}\text { Proportion of state-owned enterprises in the values added of } \\
\text { industrial enterprises above designated size (take the logarithm) }\end{array}$ \\
\hline & $\begin{array}{l}\text { Proportion of heavy industry } \\
\text { in industrial enterprises } / \%\end{array}$ & $\mathrm{LNhr}_{\mathrm{t}}$ & $\begin{array}{l}\text { Proportion of heavy industry in the values added of industrial } \\
\text { enterprises above designated size (take the logarithm) }\end{array}$ \\
\hline & $\begin{array}{l}\text { Fixed assets per unit of industrial } \\
\text { value added / thousand US\$ }\end{array}$ & LNinin $_{t}$ & $\begin{array}{c}\text { Value added of industrial enterprises above designated size / } \\
\text { total fixed assets (take the logarithm) }\end{array}$ \\
\hline \multirow{3}{*}{$\begin{array}{l}\text { Instrumental } \\
\text { variable }\end{array}$} & Fiscal revenue / million US\$ & LNcshou $_{t}$ & Local government budgetary revenue (take the logarithm) \\
\hline & $\begin{array}{l}\text { Total profits and taxes of industrial } \\
\text { enterprises / million US\$ }\end{array}$ & LNlishui $_{t}$ & $\begin{array}{l}\text { Total profits and taxes of industrial enterprises above designated } \\
\text { size (take the logarithm) }\end{array}$ \\
\hline & $\begin{array}{l}\text { Industrial enterprises' ratio of Profits } \\
\text { and taxes to total assets } / \%\end{array}$ & LNlshra $_{\mathrm{t}}$ & $\begin{array}{c}\text { Total profits and taxes / total assets of industrial enterprises } \\
\text { above designated size (take the logarithm) }\end{array}$ \\
\hline
\end{tabular}


structure adjustment on resource saving and pollutant emission reduction is not significant [20]. Therefore, the impact factors of resource saving and pollutant emission reduction in an economy can be broadly grouped into two broad categories: technological progress and the enterprises' activities with positive externalities regulated by government fiscal and tax policy (e.g., cleaner production and circular economy). Hence, this study takes the government FEECEP and the R\&D investment of industrial enterprises (reflecting the role of scientific and technological progress) as the core explanatory variables when estimating the econometric model. At the same time, considering that structural adjustment has a certain effect of energy saving and pollutant emission reduction, as well as the impact of investment in fixed assets on technological progress, this study takes the proportions of state-owned enterprises and heavy industry in the whole industry, and the fixed asset investment per unit of industrial value added as non-core explanatory variables.

In addition, some studies have shown that the degree of fiscal decentralization also has a significant impact on the effect of FEECEP [21]. In this study, the degree of fiscal decentralization is also included among the non-core explanatory variables. The changes of pollutant emission intensity and resource consumption intensity can affect the government fiscal expenditure decision, thus increasing or decreasing FEECEP. This means that there are endogenous issues in the model. With reference to the criteria that the instrumental variables be highly related to the explanatory variables but not to the explained variables, the amount of fiscal revenue, the profits and taxes of industrial enterprises, and the profit and tax rate of industrial enterprises were selected as the instrumental variables for the estimation of econometric model. The symbols and meanings of the explanatory variables and the explained variables are shown in Table 2.

Because the econometric model requires that the data must be stationary when doing the regression analysis between the explained variables and the explanatory variables, the series data should be logarithmized. In order to eliminate the influence of price fluctuations, the industrial value added data, FEECEP, industrial enterprises expenditure on R\&D, and other data used in this paper are all processed by the GDP deflator. The GDP deflator refers to the ratio of the nominal GDP of that year to the GDP calculated in fixed price of a given year.

\section{Model Hypothesis and Basic Models}

The purpose of government expenditure for energy conservation and environmental protection is to save resources and reduce pollutant emissions, so there is a negative correlation between it and resource consumption intensity or pollutant emission intensity. Scientific and technological progress can promote resource saving and pollutant emission reduction, so it is also negatively correlated with resource consumption intensity or pollutant emission intensity.

For this study, seven basic models were designed.

$$
\begin{aligned}
& \text { LNenergy }_{i, t}=\beta_{11}+\beta_{12} L N e c_{i, t}+\beta_{13} L N r d_{i, t}+\beta_{14} L N c f_{i, t} \\
& +\beta_{15} L N h r_{i, t}+\beta_{16} L N g p_{i, t}+\beta_{17} \operatorname{LNinin}_{i, t}+u_{i, t} \\
& \mathrm{LNh} 2 \mathrm{o}_{i, t}=\beta_{21}+\beta_{22} L N e c_{i, t}+\beta_{23} L N r d_{i, t}+\beta_{24} L N c f_{i, t} \\
& +\beta_{25} L N h r_{i, t}+\beta_{26} L N g p_{i, t}+\beta_{27} \operatorname{LNinin}_{i, t}+u_{i, t} \\
& \mathrm{LNemso}_{i, t}=\beta_{31}+\beta_{32} \mathrm{LNec}_{i, t}+\beta_{33} L N r d_{i, t}+\beta_{34} L N c f_{i, t} \\
& +\beta_{35} L N h r_{i, t}+\beta_{36} L N g p_{i, t}+\beta_{37} L_{N i n i n}, t+u_{i, t} \\
& \text { LNemnox }_{i, t}=\beta_{41}+\beta_{42} L N e c_{i, t}+\beta_{43} L N r d_{i, t}+\beta_{44} L N c f_{i, t} \\
& +\beta_{45} L N h r_{i, t}+\beta_{46} L N g p_{i, t}+\beta_{47} L_{N i n i n}, t+u_{i, t} \\
& \operatorname{LNemand}_{i, t}=\beta_{51}+\beta_{52} L N e c_{i, t}+\beta_{53} L N r d_{i, t}+\beta_{54} L N c f_{i, t} \\
& +\beta_{55} L N h r_{i, t}+\beta_{56} L N g p_{i, t}+\beta_{57} L_{N i n i n} i, t+u_{i, t} \\
& \operatorname{LNemyan}_{i, t}=\beta_{61}+\beta_{62} L N e c_{i, t}+\beta_{63} L N r d_{i, t}+\beta_{64} L N c f_{i, t} \\
& +\beta_{65} L N h r_{i, t}+\beta_{66} L N g p_{i, t}+\beta_{67} L_{N i n i n}+u_{i, t} \\
& \operatorname{LNemcod}_{i, t}=\beta_{71}+\beta_{72} L N e c_{i, t}+\beta_{73} L N r d_{i, t}+\beta_{74} L N c f_{i, t} \\
& +\beta_{75} L N h r_{i, t}+\beta_{76} L N g p_{i, t}+\beta_{77} L_{N i n i n}^{i, t}+u_{i, t}
\end{aligned}
$$

\section{Analysis on the Effect of Resource Saving and Pollutant Emission Reduction Caused by Government FEECEP}

Still taking the reduction of sulfur dioxide emissions as an example, from the perspective of statistics published by the government at present, it is easy to calculate the sulfur dioxide emission intensity $\left(\right.$ emso $\left._{i, t}\right)$ of every prefecture-level cities in recent years, and the annual industrial added value $\left(i n g d p_{i, t}\right)$ is also a known quantity. Therefore, annual amount of pollutant emission reduction $\left(Q S O_{i, t}\right)$ is also easy to calculate, as shown in Formula (9).

$$
Q S o_{i, t}=\operatorname{ingdp}_{i, t} \times\left(\frac{\text { qemso }_{i, t-1}}{\operatorname{ingdp}_{i, t-1}}-\frac{q e m s o_{i, t}}{\operatorname{ingdp}_{i, t}}\right)
$$

$Q_{s O_{i, t}}$ is the amount of industrial sulfur dioxide emission reduction in the $t$-period of city $i$. qemso $o_{i, t}$ is the amount of industrial sulfur dioxide emission in the $t$-period of city $i$. ingdp $p_{i, t}$ is the industrial added value in the $t$-period of city $i$.

The key step in calculating the emission reduction caused by government FEECEP is how to separate this kind of share from the annual total amount of pollutant emission reduction according to Model (4). With the help of the economic meaning of the model parameters, this goal can be achieved. It is assumed that, except for $\mathrm{LNemso}_{i, t}$ and $L N e c_{i, t}$, the other conditions remain unchanged. Namely, for the variables of $L N r d_{i, t}, L N c f_{i, t}$, $L N h r_{i, t}, L N g p_{i, t}, \operatorname{LNinin}_{i, t}$, and $u_{i, t}$, their values in the $t$-period are equal to their values in the $t-1$ period of city $i$. According to Model (4), the data of the $t$-period and the $t-1$ period are put into the model and then make 
the former to subtract the later, we can obtain Formula (10).

$$
L N\left(1+\frac{e m s o_{i, t}-e m s o_{i, t-1}}{e m s o_{i, t-1}}\right)=\beta_{22} L N\left(1+\frac{e c_{i, t}-e c_{i, t-1}}{e c_{i, t-1}}\right)
$$

Let $S R_{i, t}=\frac{\text { emso }_{i, t}-e^{e m s o} o_{i, t-1}}{\text { emso }_{i, t-1}}$, which is the annual change rate of sulfur dioxide emission intensity of city $i$ from the $t-1$ period to the $t$ period; let $e r_{i, t}=\frac{e c_{i, t}-e c_{i, t-1}}{e c_{i, t-1}}$ , which is the annual change rate of the government FEECEP of city $i$ from the period of $t-1$ to the period of $t$. Bringing the above formula into Formula (10) yields Equation (11).

$$
\beta_{22}=\frac{L N\left(1+S R_{i, t}\right)}{L N\left(1+e r_{i, t}\right)} \approx \frac{S R_{i, t}}{e r_{i, t}}
$$

The factors that can affect the annual sulfur dioxide emission intensity $\left(\mathrm{emso}_{i, t}\right)$ are not only the government FEECEP $e c_{i, t}$, but also the technological progress of industrial enterprises, industrial structure adjustment, and other factors. Inferred from the causal relationship, $e c_{i, t}$ will certainly help to reduce the value of emso $_{i, t}$. Assuming that the marginal cost of sulfur dioxide emission reduction does not change over time, the elasticity of emso $_{i, t}$ to the change of $e c_{i, t}$ must be greater than -1 and less than 0 . According to the definition of elasticity, the elasticity of emso $_{i, t}$ with respect to the change of $e c_{i, t}$ should be $\frac{S R_{i, t}}{e r_{i, t}}$. When the value of $e r_{i, t}$ changes from large to small, the value of $\beta_{22}$ gradually approaches the value of $\frac{S R_{i, t}}{e r_{i, t}}$. However, when the value of $e r_{i, t}$ is larger, the deviation between the value of $\beta_{22}$ and $\frac{S R_{i, t}}{e r_{i, t}}$ cannot be ignored. Assume that the elastic value of emso ${ }_{i, t}$ with respect to the change of $e c_{i, t}$ is -0.8 . The value of $e r_{i, t}$ is 0.6 (i.e. the growth rate is $60 \%$ ), and the ratio of $\beta_{22}$ to $\frac{S R_{i, t}}{e r_{i, t}}$ is -0.96 . However, when the elastic value is -0.1 , the ratio is only -0.81 . Therefore, when calculating the change rate of emso $_{i, t}$ caused by the change of $e c_{i, t}$, it cannot be solved directly by the value of $\beta_{22}$. The calculation method can be inferred from formula (11), shown as formula (12)

$$
\operatorname{RESR}_{i, t}=\left(1+e r_{i, t}\right)^{\beta_{22}}-1
$$

Here, $R_{E S R}$ is the response coefficient of the explained variable to the change of the explanatory variable, which means the change rate of emso $_{i, t}$ caused by the change of $e r_{i, t}$ under the premise that other conditions remain unchanged. Similarly, we can also calculate the change rate of emso $_{i, t}$ caused by the change of other control variables. As a matter of fact, that other conditions remain unchanged is a severe constraint which is very difficult to meet in reality. If the factors that play a leading role in the change of $\mathrm{emso}_{i, t}$ can be determined, and the rate of change in emso ${ }_{i, t}$ caused by the dominant factor is much higher than that caused by the non-dominant factor, it is still of practical reference value to deduce the role of the dominant factor played in the change of the explained variable by using the response coefficient of the explained variable to the change of the explanatory variable $\left(R E S R_{i, t}\right)$.

Assuming that there are $m$ core explanatory variables and $n$ non-core explanatory variables, the sum of the change rate of emso ${ }_{i, t}$ caused by these two kind of factors can be calculated by Formulas (13) and (14).

$$
\begin{aligned}
& D S R_{i, t}=\sum_{d=1}^{m} R E S R_{i, d, t} \\
& O S R_{i, t}=\sum_{o=1}^{n} R E S R_{i, o, t}
\end{aligned}
$$

$D S R_{i, t}$ is the sum of the change rate of emso $_{i, t}$ caused by the core explanatory variables in the $t$ period of city $i$;OSR $R_{i, t}$ is the sum of the change rate of emso ${ }_{i, t}$ caused by non-core explanatory variables in the $t$ period of city $i$. Since both of these are partial effects calculated under the same assumption that other conditions remain unchanged, they must be revised when determining their real effects.

Let $T S R_{i, t}$ be set as the total change rate of emso $_{i, t}$ in the $t$ period of city $i$. There is an issue of goodnessof-fit in the econometric model, which manifests to what extent the fluctuation amplitude of the explained variable can be explained by the estimated model [19]. When calculating the share of an explanatory variable in the total change rate of the explained variable, the value of $T S R_{i, t}$ should be multiplied by the value of the determinable coefficient $\mathrm{R}^{2}$, and the corrected index here are renamed $R T S R_{i, t}$. When the change rate caused by the non-core explanatory variable is relatively small, it is reasonable to use $R T S R_{i, t}$ minus $O S R_{i, t}$ to represent the change rate of emso $_{i, t}$ caused by the real core variable. However, if the annual change values of a non-core explanatory variable in some periods is very large, the coefficients estimated through regression analysis would contorted greatly, making the roles of core explanatory variables inferred from econometric model far away from the real situation. In order to avoid the above situation, a flexible calculation method can be considered, as shown in Formula (15).

$$
R D S R_{i, t}=D S R_{i, t}+O S R_{i, t} \times \frac{1}{l} \sum_{j=1}^{l} \sum_{t=T_{1}}^{t=T_{2}} \frac{\left(R T S R_{j, t}-O S R_{j, t}-D S R_{j, t}\right)}{O S R_{j, t}}
$$

$R D S R_{i, t}$ is the revised sum of the change rate of emso $_{i, t}$ caused by the core explanatory variables in the $t$ period of city $i$, and $l$ is the number of prefecturelevel cities in the assumed province. The change of the non-core explanatory variable will counteract or increase the effect of the core explanatory variable. The symbol AVROD is used to represent the sector of $\frac{1}{l} \sum_{j=1}^{l} \sum_{t=\mathrm{T}_{1}}^{t=\mathrm{T}_{2}} \frac{\left(R T S R_{j, t}-O S R_{j, t}-D S R_{j, t}\right)}{O S R_{j, t}}$ in the Formula (15). If there is an abnormally high value of $\frac{\left(R T S R_{j, t}-O S R_{j, t}-D S R_{j, t}\right)}{O S R_{j, t}}$, it will greatly increase its influence on the value 
of AVROD. In order to prevent a small number of extremes from excessively affecting the size of the value of AVROD, we can delete the top $10 \%$ of the largest value of $\frac{\left(R T S R_{j, t}-O S R_{j, t}-D S R_{j, t}\right)}{O S R_{j, t}}$ from the sample data when calculating the value of AVROD.

If $R D S R_{i, t}$ is set to be equal to $\alpha D S R_{i, t}$, the effect value of a single core explanatory variable's change can be calculated by Formula (16).

$$
R D S R_{i, d, t}=\alpha R E S R_{i, d, t}
$$

$R D S R_{i, t}$ is the change rate of the explained variable caused by the change of the $d$ core explanatory variable in $t$ period in city $i$; RESR $R_{i t}$ is the response coefficient of the explained variable of city $i$ to the change of the $d$ explanatory variable in $t$ period, as shown in Formula (12).

\section{The Calculation Method of the Total Amount of Resource Saving and Emission Reduction Caused by the Government FEECEP}

The growth rate of this expenditure in each year can be calculated when the time series data of government FEECEP are obtained. The growth rate is multiplied by $R D S R_{i, t}$, which is the change rate of the explained variable caused by the change of the $d$ core explanatory variable in city $i$ (the $d$ core explanatory variable here refers to the government FEECEP, the calculation process is shown in Formula (16)), we can obtain the change rate of pollutant emission intensity, and the amount of pollutant emission reduction caused by this expenditure in the corresponding year can then be calculated. Taking the calculation of energy conservation amount as an example, the calculation process is shown in Formula (17).

$$
Q E_{i, t}=\text { energy }_{i, t-1} \times R D S R_{i, t} \times e c r_{t} \times \text { indus }_{t}
$$

$Q E_{i, t}$ is the amount of energy saving in the $t$ period of city $i$; energy $y_{i, t-1}$ is the energy consumption intensity in the $t$ period of city $i$; ecr $r_{i,}$ is the change rate of government energy saving and environmental protection expenditure in the $t$ period of city $i$. The calculation process can be seen in Formula (18). indus is the industrial added value in the $t$ period of city $i$.

$$
e c r_{i, t}=\frac{e c_{i, t}-e c_{i, t-1}}{e c_{i, t-1}}
$$

$e c_{i, t}$ is the amount of government FEECEP in the $t$ period of city $i$.

Positive externality, such as the implementation of cleaner production or the development of the circular economy, will, like a fixed asset investment, play a stable role in a period of time once an operating mechanism or mode of the enterprise is formed, until it enters another life cycle. Therefore, when estimating the effect of resource saving and emission reduction caused by government FEECEP, it is necessary to set a period of time during which the effects caused by government FEECEP continue to play a role.

With reference to the national regulations on the depreciation life of industrial fixed assets, this study considers the effect caused by FEECEP over three periods of time: 10 years, 15 years, and 20 years in order to investigate their impact on performance evaluation. That is, enterprises' activities and its relative facilities with positive externality caused by this expenditure can operate continuously for 10 years, 15 years, and 20 years. During this period, in principle, there is no need for additional government investment, and the effects caused by FEECEP will continue to play a role. Taking the energy-saving effect that would last for 10 years as an example, the government FEECEP during the $t$ period has led to a decrease in the energy consumption intensity, which is not directly caused by governmental behavior, but is indirectly realized through guiding enterprises to carry out economic activities with positive externalities such as the renovation of production equipment, the development of circular economy or cleaner production. During the t period, the amount of energy saving generated by this expenditure will be the cumulative amount of 10 years, which is calculated by Formula (19).

$$
T Q E_{i, t}=\left(\text { energy }_{i, t-1} \times R D S R_{i, t} \times e c r_{i, t}\right) \times 10 \times \text { indus }_{i, t}
$$

$T Q E_{i, t}$ is the total amount of energy saving caused by the government FEECEP during the $t$ period of city $i$. Calculating the total amount of energy saving based on formula (24) means that the city's industrial production scale remains unchanged during this period. If the energy-saving effect of government FEECEP remains unchanged in the situation that the industrial scale expanded continually, then $T Q E_{i, t}$ should be calculated by Formula (20).

$T Q E_{i, t}=\left(\operatorname{energy}_{i, t-1} \times R D S R_{i, t} \times e c r_{i, t}\right) \times\left(\sum_{j=0}^{9}\right.$ indus $\left._{i, t+j}\right)$

$\Sigma_{j=0}^{9}$ indus $_{i, t+j}$ is the sum of the industrial added value of the city $i$ in 10 years, and $j=1,2, \ldots, 9$, which represents the $t$ period and the following 9 years.

\section{Calculation of Environmental Value per Unit Pollutant Emission Reduction}

The environmental value of resource saving and pollutant emission reduction can be regarded as reduced environmental pollution loss [2]. Under this idea, the environmental value of the unit pollutant emission reduction or unit resource saving can be calculated by using the accounting method of environmental pollution loss, which mainly includes damage-based accounting method and cost-based accounting method [22]. The cost-based accounting method regards 
the disposal cost of environmental pollutants as the loss caused by discharging them into the environment. In the field of the internalization of positive externality, the environmental value of unit pollutant emission reduction and resource saving defined by pollutants disposal costs is often underestimated. The reasonable logic is that the enterprise has the motivation to carry out economic activities with positive externalities when the profit rate of investment in this field is close to that in other fields. According to this thinking, this study takes the investment profit margin into account when determining the environmental value of pollutant emission reduction and resource saving. The calculation method is shown in Formula (21).

$$
P_{i, t, j}=\frac{b f_{i, t, j} \times\left(1+r_{i, t}\right)}{Q P_{i, t, j}}
$$

$P_{i, t, j}$ is the environmental value of the $j$ pollutant emission reduction in the $t$ period of city i (unit price); $b f_{i, t, j}$ is the operating cost of the $j$ pollutant disposal facility in the $t$ period of city $i ; r_{i, t}$ is the industrial enterprises' ratio of profits to cost in the $t$ period of city $i$; $Q P_{i, t, j}$ is the amount of the $j$ pollutant removed in the city $i$ during the $t$ period.

For the sake of convenience, taking the proportion of the amount of a pollutant removed in each year to the total amount of the pollutant removed during the whole studied period as a weight, calculate each pollutant's weighted average environmental value in each city respectively, which is used as the basic parameter to calculate the total environmental value of resource saving and pollutant emission reduction caused by FEECEP in every prefecture-level city. The calculation method is shown in Formula (22).

$$
P_{i, j}=\sum_{t=T_{1}}^{t=T_{2}}\left(\frac{Q P_{i, t, j} \times P_{i, t, j}}{\sum_{t=T_{2}}^{t=T_{2}} Q P_{i, t, j}}\right)
$$

When calculating the environmental value of resource saving and pollutant emission reduction caused by government fiscal energy conservation and environmental protection in whole assumed province, the environmental value of unit emission reduction of every pollutant is needed. Taking the proportion of the amount of a pollutant removed in each prefecturelevel city to the total amount of the pollutant removed in the whole assumed province as a weight, calculate each pollutant's weighted average environmental value $(p)$ respectively, which is used as the key parameter to calculate the environmental value of resource saving and emission reduction caused by FEECEP of the whole assumed province, as shown in Formula (23).

$$
P_{j}=\sum_{i=1}^{l}\left(\frac{Q P_{i, j} \times P_{i, j}}{\sum_{i=1}^{l} Q P_{i, j}}\right)
$$

$P_{j}$ is the weighted average environmental value per unit of $j$ pollutant emission reduction in the assumed Province; $Q P_{i, j}$ is the removal amount of the $j$ pollutant in city $i$ during the period from $T_{1}$ to $T_{2} ; P_{i, j}$ is the weighted average environmental value per unit of emission reduction of the $j$ pollutant in city $i, i=0,1$, $2, \ldots, l$, which represents $l$ prefecture-level cities in the assumed Province.

\section{Accounting Method of Environmental Value of Resource Saving}

The cost-saving benefits caused by resource saving have been obtained by enterprises, so they cannot be viewed as positive externalities. However, the emission reduction of pollutants caused by resource saving should be. The resource saving involved in this research includes two parts: energy saving and water saving. When calculating this kind of positive externality, the environmental value of energy saving and water saving should be treated differently. In terms of energy consumption, energy saving means less emissions of sulfur dioxide, nitrogen oxide, carbon dioxide, smoke and dust. The emission reduction effect of sulfur dioxide, nitrogen oxide, and smoke dust has been reflected in the decrease of pollutant emission intensity per unit of industrial output. Therefore, this study only takes into account the carbon emission reduction effect when calculating the environmental value of energy saving. Water saving is different from energy saving, the effect of water saving does not include the emissions reduction of COD, ammonia nitrogen, and other water pollutants. From the opposite point of view, water saving can be viewed as the increase of water environmental capacity. Therefore, the environmental value of water saving can be measured by the environmental pollutants that the same amount of fresh water can hold, which is approximately equal to the content of pollutants in industrial wastewater discharged in line with relevant national standard. Formula (24) can be used to calculate the emission reduction of pollutants caused by resource saving.

$$
Q P_{i, c, t}=T Q E_{i, t} \times \alpha
$$

$Q P_{i, c, t}$ is the total amount of greenhouse gas emission reduction caused by government FEECEP in the $t$ period of city $i$; $T Q E_{i, t}$ is the total amount of energy saving (the total amount of water saving when calculating ammonia nitrogen and COD) in the $t$ period of city $i, \alpha$ is the carbon dioxide emission factor per unit of standard coal. When calculating the environmental value of water saving, $Q P_{i, c, t}$ is the total amount of emission reduction of COD or ammonia nitrogen caused by government FEECEP in the $t$ period of city $i ; \alpha$ is the concentration of COD or ammonia nitrogen per unit of industrial wastewater. Environmental pollutant discharge standards vary from country to country, which determines that the value of a pollutant emission factor in a country is often different from other countries. 


\section{Positive Externality Monetization Measurement Model}

With the help of the econometric model parameters, this study calculates the positive externalities of industrial enterprises' relevant economic activities caused by government FEECEP in each prefecturelevel cities in the assumed Province in recent years. The calculation method is shown as Formula (25).

$$
E x_{i, t}=\sum_{j=1}^{6} T Q P_{i, j} \times P_{i, j}
$$

Ext $_{i, t}$ is the positive externality of industrial enterprises caused by the government FEECEP in the $t$ period of city $i$; TQP $P_{i, t}$ is the total emission reduction of the $j$ pollutant in city $i$, and its calculation method is the same as that of energy saving, which is shown as Formula (19) and Formula (20), $j=0,1,2, \ldots, 6$, which represents serial number of five industrial environmental pollutants, including sulfur dioxide, nitrogen oxide, smoke and dust, ammonia nitrogen, chemical oxygen demand, and the greenhouse gas carbon dioxide; $P_{i, j}$ is the environmental value per unit of emission reduction of the $j$ pollutant in city $i$. The industrial positive externality scale (SDEx) of the whole assumed Province caused by the government FEECEP is calculated as shown in Formula (26). $P_{j}$ is the environmental value generated per unit of emission reduction of the $j$ pollutant of assumed Province.

$$
S D E x_{t}=\sum_{i=1}^{l} \sum_{j=1}^{6}\left(T Q P_{i, j} \times P_{j}\right)
$$

\section{Performance Evaluation Index of the Government FEECEP}

Fig. 1 shows that the government input is equal to the output $(\mathrm{AB}=\mathrm{AC})$ when the positive externalities of industrial enterprises' economic activities are completely internalized. Since $\mathrm{AB}$ and $\mathrm{AC}$ intersect at the same intersection as $\mathrm{MB}$ and $\mathrm{MC}$, that $\mathrm{AC}$ is equal to $\mathrm{AB}$ also means that $\mathrm{MB}$ is equal to $\mathrm{MC}$. At this time, the performance level of government FEECEP is the highest.

The econometric model only simulates the functional relationship between the explained variable and the explanatory variables in a statistical sense. It reflects the objective change law between the data. The model parameters have the meaning of "average" when explaining the relationship between the explained variable and the explanatory variables, that is, during the investigation period, the explained variable and the explanatory variables show a functional relationship in the average sense. Therefore, the government FEECEP over a period of time and its effect of resource saving and pollutant emission reduction can be regarded as a whole entity. The performance of government FEECEP is optimal when the input is equal to its output. On the basis of this logic, the performance evaluation index of government FEECEP can be constructed.

Since the use of government fiscal funds does not take profit as the goal, when calculating the positive externality scale of industrial enterprises' activities with positive externality, the issue of discount rate could be excluded in the process of calculating the environmental value of the RSPER. According to the connotation of internalization of externality, government should compensate the loss of the industrial enterprises' private benefits generated by implementing activities with positive externalities, which is equal to the part of enterprises' private benefits that is lower than the social benefits of this kind of activities, and the internalization degree of positive externality can be used as the evaluation standard of the performance of government FEECEP performance in the whole industrial system. Based on this idea, we construct a performance evaluation index, which is shown as Formula (27).

$$
\operatorname{Enp}_{i}=\frac{\sum_{t=T_{1} E x_{i, t}}^{t=T_{2}}}{\beta \sum_{t=T_{1}}^{t=T_{2} e c_{i, t}}}
$$

$E_{n, t}$ is the performance evaluation index of government FEECEP in city $i$ (which is also suitable for the performance evaluation of whole assumed Province) from $T_{1}$ to $T_{2} ; e c_{i, t}$ is the amount of this kind of expenditure in the $t$ period of city $i ; \beta$ is the proportion of government energy conservation and environmental protection funds invested in the industrial field. But this proportion has an obvious characteristic of spatiotemporally fluctuations, and the relevant data are difficult to obtain. Drawing on experience of the scenario analysis method, we assign five values in turn to parameter $\beta: 1,0.85,0.7,0.55$, and 0.4 in order to take into account the actual situation of different regions when evaluating the performance of government FEECEP.

If government FEECEP is regarded as a cost and positive externalities caused by this kind of expenditure as its benefit, the average income is equal to the average cost when the positive externalities of industrial enterprises' relevant activities are completely internalized (Fig. 1), then the value of Enp should be equal to 1 .

Under the guidance of this kind of expenditure, the industrial enterprises' activities with positive externality would be developed. In Fig. 1, as the development level of this kind of activities reaches a point marked $\mathrm{Q}_{1}$, $\mathrm{MB}$ begins to decline and $\mathrm{MC}$ begins to rise; the ratio between $\mathrm{AB}$ and $\mathrm{AC}$ increases with the increase of this kind of fiscal expenditure; the closer the development level of this kind of activities is to $\mathrm{Q}_{0}$, the closer the value of Enp $p_{t}$ is to 1; After crossing $\mathrm{Q}_{0}$, the value of

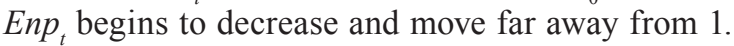

According to the difference between the actual value of the performance evaluation index each year and 1, the performance of FEECEP is divided into five grades: that the value is bigger than 0.9 is high-efficient level, 
that 0.8 to 0.9 is good level, that 0.7 to 0.8 is medium level, that 0.6 to 0.7 is qualified level, and that less than 0.6 is inefficient level.

\section{Conclusion}

To sum up, this study gets the following conclusions: (1) The internalization degree of positive externalities is a suitable indicator for evaluating the performance of government expenditures for resource conservation and environmental protection. It also gives theoretical support for the government to provide preferential policies and financial subsidies for corporate behaviors with positive externalities under market economic conditions. Regarding the internalization degree of positive externalities as the basis for fiscal expenditure structural adjustment on resource conservation and environmental protection can effectively prevent the government from giving excessive subsidies to corporate behaviors with positive externalities, thereby improving the resource allocation efficiency of market economic mechanisms.

(2) The current research on the internalization of externalities has achieved certain research results at micro-level of enterprise and meso-level of industry. However, the research progress in the macro-level of region is relatively slow, and it is difficult to complete the monetization measurement of positive externality. There are two main obstacles: one is the imperfect statistical data of government fiscal expenditure for resource conservation and environmental protection, and the other is the blurry boundary of enterprise' activity with positive externalities.

(3) The econometric method is a typical black box method. The econometric model can be estimated to obtain the functional relationship between key variables as long as the input and output data of the system are known. This provides a path for circumventing the issue of blurry boundary of the economic activity with positive externalities and inferring the effects of government fiscal expenditure for resource conservation and environmental protection.

(4) The main work of this study is to establish a method, that is, how to use the estimated parameters of an econometric model to indirectly calculate the effects of pollutant emission reduction and resource conservation caused by government fiscal expenditure for resource conservation and environmental protection. Among them, how to overcome the difficulties caused by the strong assumption of a parameter's economic meaning, that is, other conditions remain unchanged, is the key to the established method, and it has an important impact on whether the calculation results have policy guiding significance.

There is a hypothesis employing a parameter of an estimated econometric model to deduce the effects of resource saving and environmental pollutant emission reduction caused by government fiscal expenditure on this field, that is, every region whose data were incorporated in the panel data has a similar fiscal expenditure structure of resource conservation and pollutant emission reduction. This assumption is relatively close to reality when the participating regions are relatively close geographically and their differences of industrial structures are not big. If the development levels of the participating regions are very different, and the differences of industrial structure are very big, it will greatly affect the accuracy of the estimated results, and thus reduce the policy guiding significance of the research results.

\section{Acknowledgments}

This study was funded by Key Deployment Projects of Innovation Academy for Green Manufacture, Chinese Academy of Sciences (IAGM-2019-A16) ,Shandong Provincial Natural Science Foundation, China (ZR2021MG040) and Shandong Provincial Humanities and Social Project, China (2021-JCGL-01). We also thank the administrative bureaus of prefecturelevel cities in Shandong province for their assistance in data collection.

\section{Conflicts of Interest}

The authors declare no conflict of interest.

\section{References}

1. WANG J.N. Environmental Economics - Theory, Methods and Policies.; Tsinghua University Press: Beijing, China, 53, 1994.

2. YU H.L.,YAN Y.N., DONG S.C. A System Dynamics Model to Assess the Effectiveness of Governmental Support Policies for Renewable Electricity. Sustainability. 11 (12), 27, 2019.

3. DING H.P.,HE M.F., DENG C. Lifecycle approach to assessing environmental friendly product project with internalizing environmental externality. J. Clean. Prod. 66, 128, 2014

4. EIDELWEIN F.,COLLATTO D.C.,RODRIGUES L.H., LACERDA D.P., PIRAN F.S. Internalization of environmental externalities: Development of a method for elaborating the statement of economic and environmental result. J. Clean. Prod. 170, 625, 2018.

5. WANG C.B.,ZHANG L.X., ZHOU P., CHANG Y., ZHOU D.Q., PANG M.Y., YIN H. Assessing the environmental externalities for biomass- and coal-fired electricity generation in China: A supply chain perspective. J. Environ. Manage. 246, 758, 2019.

6. RODRIGUEZ-VALLEJO D.F., GUILLEN-GOSALBEZ G., CHACHUAT B. What Is the True Cost of Producing Propylene from Methanol? The Role of Externalities. ACS Sustain. Chem. Eng. 8 (8), 3072, 2020.

7. XIA B.Q., QIANG M.S., JIANG H.C., WEN Q., AN N., ZHANG D.C. Phase-based externality analysis for large 
hydropower projects. Environ. Impact Assess. Rev. 80, 12, 2020.

8. ŠTREIMIKIENE D. Review of internalization of externalities and dynamics of atmospheric emissions in energy sector of Baltic States. Renew. Sust. Energ. Rev. 70, 1131, 2017.

9. DING H.P., LIU Q., ZHENG L. Assessing the economic performance of an environmental sustainable supply chain in reducing environmental externalities. Eur. J. Oper. Res. 255 (2), 463, 2016.

10. WANG Z.Z., TSAI Z.L., FU J., ZHAO L.Y., YANG L.L. Internalization of negative external cost of green logistics and incentive mechanism. Adv. Mech. Eng. 9 (8), $1687814017715420,2017$.

11. FERNANDES P., VILACA M., MACEDO E., SAMPAIO C., BAHMANKHAH B., BANDEIRA J.M., GUARNACCIA C., RAFAEL S., FERNANDES A.P., RELVAS H.,BORREGO C., COELHO M.C. Integrating road traffic externalities through a sustainability indicator. Sci. Total Environ. 691, 483, 2019.

12. ZIOLO M., FILIPIAK B.Z., BAK I.CHEBA K., TIRCA D.M., NOVO-CORTI I. Finance, Sustainability and Negative Externalities. An Overview of the European Context. Sustainability. 11 (15), 35, 2019.

13. YU H.L., DONG S.C., LI F. A System Dynamics Approach to Eco-Industry System Effects and Trends. Pol. J. Environ. Stud. 28 (3), 1469, 2019.

14. KLAASSEN G., RIAHI K. Internalizing externalities of electricity generation: An analysis with MESSAGEMACRO. Energ. Policy. 35 (2), 815, 2007.

15. HOLMGREN K., AMIRI S. Internalising external costs of electricity and heat production in a municipal energy system. Energ. Policy. 35 (10), 5242, 2007.

16. NGUYEN K.Q. Internalizing externalities into capacity expansion planning: The case of electricity in Vietnam. Energy. 33 (5), 740, 2008

17. FRIEDRICH R., BICKEL P. estimation of external costs using the impact pathway approach: results from the externe project series. TA-Datenbank-Nachrichten. 10, 74, 2001.

18. KORHONEN J., HONKASALO A., SEPPALA J. Circular Economy: The Concept and its Limitations. Ecol. Econ. 143, 37, 2018.

19. WOOLDRIDGE J.M., Introductory Econometrics: A Modern Approach, Fifth ed.; China Renmin University Press: Beijing, China, 2015.

20. DONG S.C., YU H.L., LI Y., LI Z.H., LI F., LI F.J. China industrial energy saving: analysis on driving factors of development of circular economy. China Population, Resources and Environment. 26 (6), 27, 2016.

21. ZHU X.H., LU Y.Q. Pollution governance effect on environmental fiscal and taxation policy: based on region and threshold effect. China Population Resources and Environment. 27 (1), 83, 2017.

22. YANG D.H., LI H.L. Environmental Pollution Loss Accounting Based on Damage and Cost -The Case of Shandong Province. China Industrial Economics. (7), 125, 2010. 